\title{
Management of chemically contaminated bodies
}

\author{
Adrienne Edkins MSc Virginia Murray FFOM FRCPath
}

J R Soc Med 2005;98:141-145

In the world today over 23 million chemical compounds are known to man. ${ }^{1}$ Of these chemicals, about 70000 are in regular use and some 500 new ones are introduced every month into the market. ${ }^{2}$ The extensive use of chemicals in industrial processes and their storage, disposal and transport present hazards of chemical accidents (incidents) with the potential to harm humans and the environment. The mass disaster at Bhopal, ${ }^{3}$ the sarin subway attacks in Tokyo ${ }^{4}$ and the Lake Nyos incident ${ }^{5}$ have increased public awareness of the dangers of large acute chemical incidents in modern society.

The majority of chemical incidents can do harm if incorrectly managed. The role of public health agencies, emergency response agencies, health providers and related organizations is to prevent, anticipate and respond to chemical incidents so as to reduce the impact on man and his environment. ${ }^{6}$ All these agencies have a duty to ensure the health and safety of their personnel in such incidents. ${ }^{7}$ There are well-defined procedures in place for the management of chemical incidents, including advice on incident scene management, decontamination of casualties and use of personal protective equipment for emergency responders. ${ }^{6,8-10}$ These guidelines are designed to contain the hazards of a chemical incident and minimize the environmental and human impact. However, in certain cases, chemical incidents have resulted in a spread of contamination from the scene to other locations. ${ }^{11,12}$ This contamination arising from activities subsequent to the actual chemical incident is known as secondary contamination. A hospital emergency room may be contaminated by chemicals from a patient who has primary contamination with material from the scene of the incident. Secondary contamination can occur from a patient even after death and may pose a serious health risk to persons in contact with the body.

Recent incidents of secondary chemical contamination from human fatalities have revealed a need for a plan to manage chemically contaminated bodies effectively. Incidents involving chemically contaminated victims have resulted in confusion and adverse health effects in responders. ${ }^{13-15}$ The absence of guidance on the efficient

Chemical Hazards and Poisons Division (London), Health Protection Agency, Guy's and St Thomas' Hospital NHS Trust, Avonley Road, London SE14 5ER, UK Correspondence to: Professor Virginia Murray

E-mail: Virginia.Murray@gstt.nhs.uk management of chemically contaminated victims has increased the negative impact of these incidents. This paper aims to promote awareness of the potential impact of secondary contamination from chemically contaminated victims and offers preliminary guidance to those involved.

\section{CASE EXAMPLES OF SECONDARY CONTAMINATION INCIDENTS}

The following accounts describe the main events surrounding incidents in which a chemically contaminated body was encountered and serve to highlight the risks and difficulties associated with safe management.

\section{Incident 1: suicide by ingestion of aluminium phosphide in Australia ${ }^{13}$}

The patient was found collapsed at the roadside after ingestion of aluminium phosphide - a rodenticide that produces a toxic gas, phosphine, on contact with moisture. He was transferred to the accident and emergency department $(A \& E)$ of the local hospital by ambulance, where he died.

The A\&E staff noticed a 'garlic like' smell and suffered headaches and nausea. Once they realized the body was emitting phosphine they placed it in a gas-tight chemicalresistant body bag. The bag began to inflate from continuing production of gas from the body. The body was therefore enclosed in a second body bag and a hazardous materials drum and buried with the aid of earth-moving equipment.

\section{Incident 2: suicide by exposure to aluminium phosphide in the UK ${ }^{14}$}

The patient was found alive by emergency personnel in the cellar of his home. He had been exposed to a lethal dose of solid aluminium phosphide. The patient, together with an open metal canister bearing a toxic hazard warning, was transferred to A\&E where he died. The attending staff noticed a smell of garlic and experienced symptoms including nausea, headaches and dizziness. However, the assumption was that one of the team had had garlic for lunch. None of the A\&E team immediately commented on the smell. It was only when a neighbouring emergency treatment area became contaminated with the smell that staff realized the body was releasing phosphine. The air conditioning was stopped and the department was 
evacuated and decontaminated. Access to the department was blocked for 15 hours, during which time seven patients were diverted to other hospitals. In addition the ambulance used to transport the patient required decontamination and was out of use for 11 hours. The body was moved to a wellventilated area where it was placed in two normal polyvinylchloride body bags inside a plastic lined coffin by fire personnel wearing personal protective equipment and cremated. The management of the whole incident took four days.

\section{Incident 3: industrial accident involving trichloroethylene $^{16}$}

A factory worker collapsed while cleaning an 'empty' tank that had contained the industrial solvent trichloroethylene. The patient was transferred to the local A\&E department by ambulance. Biological samples were taken for toxicological analysis and he was decontaminated. The patient was transferred to the intensive care unit and died three days later. In total 9 people involved in the incident, at the site, in transit and at the hospital, were contaminated as was shown by positive toxicological results for trichloroethylene.

\section{Incident 4: industrial accident involving chlorinated hydrocarbons (the Crymlyn Burrows incident) ${ }^{17,18}$}

Two local authority workers collapsed during routine work in a sewer in Crymlyn Burrows. The men were found dead, submerged in a sludge that was later found to contain fluorinated hydrocarbon compounds. The bodies were transferred to A\&E without previous decontamination. Despite a strong chemical smell associated with the bodies, emergency responders, who were not wearing personal protective equipment, did not initially suspect a chemical incident. Adverse health effects, such as burning throat and headache, were experienced by hospital staff. The bodies were moved to a mortuary with a dedicated air supply. Fire personnel decontaminated the bodies and the mortuary. Pathologists wearing personal protective equipment performed postmortem examination of the bodies in stages over a series of days. The suits had to be ordered and delivered since none were available on site. Twenty days after the incident started, the two bodies were placed in coffins for burial and the storage fridges were decontaminated. In the days after the incident, about 300 people attended $A \& E$ with symptoms resulting from contact with the incident scene or the victims' bodies. Included among these patients were emergency responders, police and fire personnel. The A\&E set up a clinic to respond to these
A\&E department, with the exception of emergency ${ }^{19}$ calls, were diverted to nearby hospitals. The clinic was run for eight days. In total, the management of the bodies and casualties from the incident took twenty days and was a multi-agency process.

\section{LESSONS AND ISSUES HIGHLIGHTED BY THESE INCIDENTS}

These incidents highlight several issues associated with the management of chemically contaminated bodies. An incident need not produce mass chemical fatalities to have an adverse impact on human health and resources: chemical contamination of even a single victim can lead to serious contamination consequences. ${ }^{14}$ These will be much greater in the event of a mass fatality chemical incident, particularly if the chemical is persistent and highly toxic. Events such as the closure of A\&E departments and mortuaries may have serious knock-on effects on other facilities, and health professionals and emergency responders may find themselves having to work for extended periods under difficult conditions.

Chemical incidents do not have to involve exotic substances or chemical warfare agents to pose a threat of secondary contamination. The chemicals in the incidents reviewed here were common and accessible to the public. If the nature of the incident is not initially recognized, the personnel in attendance are at serious risk-health professionals, emergency responders as well as other people on the scene. The Health and Safety at Work Act (1983) states that the employer has a legal duty to ensure the safety of employees at work. Health professionals and emergency responders, therefore, have the right to be protected from the hazards associated with a chemically contaminated body. The fact that the toxic effects of many chemicals have not been fully characterized makes a realistic risk assessment for every situation difficult (Box 1).

The poor management of certain aspects of the above cases was due to a lack of defined roles and responsibilities during incident management. Personnel accepted tasks that were neither their responsibility nor defined by their 'job description'. Absence of advance guidance and lack of preparedness is a recipe for confusion. For example, if staff do not know where to get chemical-resistant body bags this will increase the time taken to manage an incident and may place added economic burdens on those who run local services in the area.

A defined and practised plan for dealing with these situations would ensure more efficient management. Staff would be less anxious about the potential hazards if the plans had been rehearsed and all personnel were informed of the emergency procedure. 


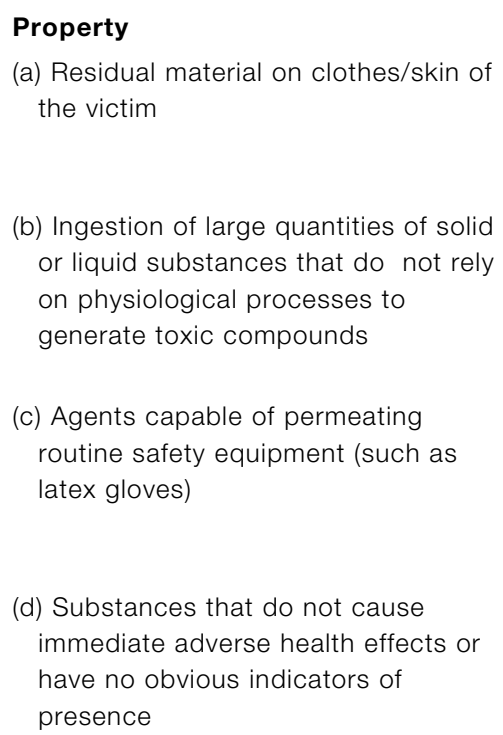

(d) Substances that do not cause immediate adverse health effects or have no obvious indicators of presence

\section{Secondary contamination hazard}

Residual chemicals in solid or liquid form on the clothing or body of the victim may be at toxic levels or produce toxic emissions

Examples: aluminium phosphide, solid and liquid cyanides, solid arsenic compounds, lewisite, chemical mustards, strong acids and alkalis

Generation of a toxic gas/compound from a solid substance (usually from contact with water, acid or alkali). Victim may continue to produce toxic compounds even after death. Body fluids such as vomit may also be contaminated and emit toxic fumes

Examples: aluminium phosphide, solid cyanides, solid arsenic compounds, chemical mustards, strong acids and alkalis

Certain chemicals, such as organic lead and mercury alkyls, are capable of permeating standard protective equipment, such as latex gloves. The toxic and persistent nature of these chemicals and their ability to be absorbed directly through the skin mean that they can be fatal in small doses and that adverse health effects are not immediately obvious Examples: mercury and lead alkyls (e.g. dimethylmercury)

Hazards may be unsuspected, since those in contact with the victim may only later experience symptoms. Personnel may not be aware of the chemical in the absence of obvious indicators, such as smell or immediate adverse health effects Examples: Phosgene and arsine

\section{EXISTING PUBLICATIONS AND LEGISLATION}

Reports and guidelines issued by agencies identified by the Chemical Hazards and Poisons Division (London) as responsible for emergency response and public health protection were reviewed for details relating to the management of chemically contaminated victims. Verbal interviews were conducted with key personnel from the Home Office Chemical, Biological, Radiological and Nuclear (CBRN) Team, members of the London ambulance services, members of emergency response groups, coroners, burial and cremation authorities and other relevant agencies. The review indicated a lack of policy and guidance on the management of incidents that include dealing with chemically contaminated victims/ bodies.

Although there is no defined guidance or policy for incidents involving chemically contaminated bodies, detailed guidelines dealing with the management of CBRN incidents do exist. ${ }^{6,9}$ The reports that mention the issue of chemically contaminated bodies are largely case histories and do not provide consolidated guidance on how best to cope. ${ }^{14,17,20}$ Guidelines and legislation to regulate the disposal of human bodies do not consider the potential risks associated with chemical contamination of a body, although there are some reports on the risks associated with contamination by infectious agents. ${ }^{10,21}$ Additionally, there is no definition of which agency or authority would be responsible for management of the chemically contaminated body, although currently the responsibility for the management of human bodies is that of the coroner in charge as defined by the Coroners Act 1988. The lack of guidance for the management of these situations results in lack of preparedness and communication problems.

\section{DEFINING THE PROCESS}

A proposal has been developed to minimize the risk of secondary contamination from the chemically contaminated victim. This can be considered as a series of steps leading to safe and respectful disposal of the body (Figure 1). Each stage of the process will have its associated risks and will require efficient management to minimize the potential for harm to those managing the incident. The general advice given is not tuned to the management of specific incidents involving chemically contaminated bodies and may not be feasible in certain cases. The guidelines (Figure 1) highlight what are thought to be the major factors that need to be considered, to act as a base from which individual organizations can define a contingency plan that suits their individual needs.

\section{CONCLUSION}

Although chemical incidents associated with chemically contaminated bodies are fortunately rare, these events can have serious implications for health and management. A proposal has been developed for management of a chemically contaminated body. The general advice arising from this may be useful to organizations in defining a tailormade, individual contingency plan to suit the needs and roles of their agency. The coroner remains at the heart of the process, with medical toxicology available 24 hours a day to provide advice and support. 


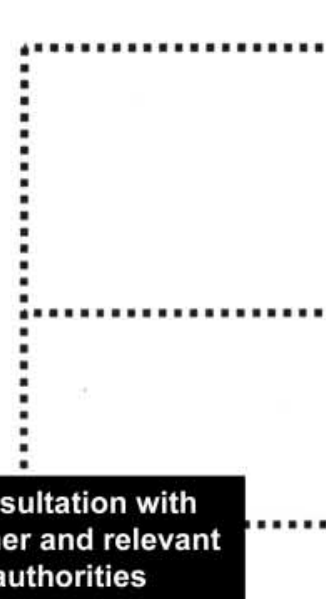

The coroner has authority over the body and his or her authorization is needed before it can be moved Consultation with the police service will be essential, especially in the event of criminal investigation Consultation with other authorities such as occupational health, poison units and burial and cremation authorities may provide useful information during the process
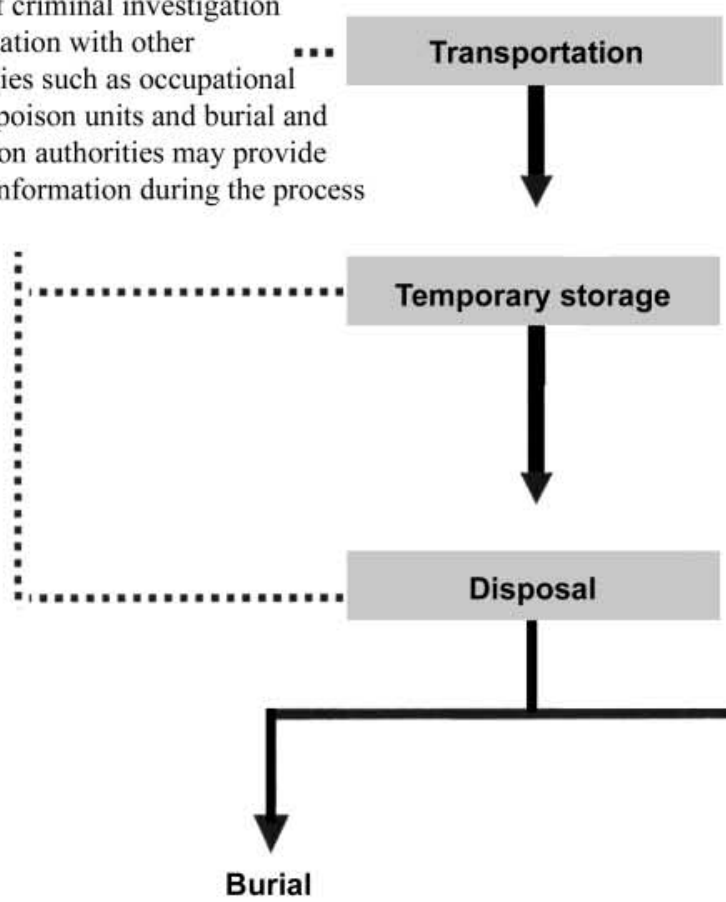

Airtight metal coffins are suggested Burial within chemical-resistant body bag Charcoal in coffin or to line grave Burial depth and location determined with respect to potential receptors, such as ground water. Consultation with the British Geological Survey in this regard is encouraged

All personnel involved in disposal should wear the correct personal protection equipment
Awareness of the potential of secondary contamination from chemical incidents

Intentional release (terrorist attack, suicide) or

unintentional release (industrial accident)

Identification by detectors or colorimetric test kits

Tentative identification by type and location of incident e.g. industrial accident or suicide

Tentative identification from clues at scene of the incident

It may not be efficient or economically viable to decontaminate a single fatality; containment may be the best policy

Decontamination of mass fatalities at a large scale event may be more feasible

Decontamination is superficial and there may still be risks associated with internal organs of the body

Containment of hazard in specialized gas-tight chemical resistant body bags

Bags are designed to be resistant to certain chemicals, but permeation will occur. Rates of permeation will vary for different chemicals

Transportation by refrigerated vehicles considered better than ambulances

May be procured either by prior arrangement or at the time of the incident

Awareness database of local facilities and availability of such vehicles essential

Refrigerated vehicles may be used as temporary storage units, depending on number of fatalities

These are a good option as they are mobile and easy to secure Fate of the vehicle subsequent to use will need to be determined (destruction or decontamination)

Pallets will be required for the bodies to prevent freezing to the refrigerated surface

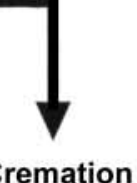

Cremation in chemical-resistant body bag

Ensure the crematorium is fitted with the regulation air filters to reduce emissions

UK facilities allow only a single body to be cremated at a time, therefore it may not be a feasible option in the event of mass fatalities

Ashes should be collected and sealed in an airtight container as they may contain residual chemicals

All personnel involved in disposal should wear the correct personal protection equipment

Decontamination of the crematorium will need to be considered

Choose a crematorium in a remote area to reduce the number of human receptors if there may be a risk associated with the release of fumes 
Acknowledgment Adrienne Edkins, a Beit Fellow for Zimbabwe 2002/2003, was supported by the Beit Trust.

\section{REFERENCES}

1 United Nations Environment Programme. Chemical Pollution: a Global Review. Geneva: UN, 1992

2 Doyle CJ, Upfal MJ, Little NE. Disaster management of massive toxic exposure. In: Haddad LM, Winchester JF, eds. Clinical Management of Poisoning and Drug Overdose. Philadelphia: WB Saunders, 1990:483-500

3 Powles H, Battrick E. Bhopal chemical disaster. CIR 2001; October, pp. 5-8

4 Okumura T, Takasu N, Ishimatsu S, et al. Report on 640 victims of the Tokyo subway sarin attack. Ann Emerg Med 1996;28:129-35

5 Murray V. Lake Nyos disaster, Cameroons, 1986. CIR 2001; October, pp. 8-9

6 Department of Health. Planning for Major Incidents: The NHS Guidance. London: Stationery Office, 1998

7 Murray V, Goodfellow F. Mass casualty chemical incidents - towards guidance for public health management. Publ Health 2002;116:2-14

8 George G, Ramsay K, Rochester M, et al. Facilities for chemical decontamination in accident and emergency departments in the United Kingdom. Emerg Med J 2002;19:453-7

9 Home Office. The Decontamination of People exposed to Chemical, Biological, Radiological or Nuclear (CBRN) Substances or Material. London: Home Office, 2003:6
10 Royal College of Pathologists. Deaths in Major Disasters: the Pathologist's Role. London: Royal College of Pathologists, 2000:39-40

11 Nosocomial poisoning associated with emergency department treatment of organophosphate toxicity-Georgia, 2000. Morbid Mortal Wkly Rep 2001;49:1156-8

12 Burgess JL. Hospital evacuations due to hazardous materials incidents. Am J Emerg Med 1999;17:50-2

13 Nocera A, Levitin HW, Hilton JMN. Dangerous bodies: a case of fatal aluminium phosphide poisoning. Med J Aust 2000;173:133-5

14 Stewart A, Whiteside C, Tyler-Jones V, et al. Phosphine suicide. CIR 2003;27:23-25

15 Murray V. Accident and Emergency department closure due to chemical contamination. CIR 1999; pp. 10-11

16 Murray V. Chemical incidents and their management. CIR 2002; July, pp. 2-4

17 Lyons RA, Wright D, Fielder HM, et al. Investigation of an acute chemical incident: exposure to fluorinated hydrocarbons. Occup Environ Med 2000;57:577-81

18 Phillips EI. The Crymlyn Burrows Incident - the Hospital Response. University of Hertfordshire, 2001

19 Armstrong A. Chemical incident responded to by University Hospital Aintree. CIR 1999; July, pp. 10-11

20 Forrest AR, Galloway JH, Slater DN. The cyanide poisoning necropsy: an appraisal of risk factors. J Clin Pathol 1992;45:544-6

21 Royal College of Pathologists. Guidelines on Autopsy Practice. London: Royal College of Pathologists, 2002:A3 